\title{
EDITORIAL
}

\section{HACIA UNA SOCIEDAD RESILENTE. UN PUNTO DE VISTA DESDE LA FACULTAD DE INGENIERÍA}

La teoría de Resiliencia, inicialmente fue utilizada para designar la resistencia de los materiales a los choques; en el campo humano especialmente en la psicología como la superación, el rehacerse ante las adversidades; el estudio de investigación se basó en testimonios de casos aprendidos para la no repetición de acontecimientos ocurridos y hechos observados en los diferentes accidentes, incidentes y casos de enfermedades.

Por otra parte, la concepción de Ingeniería de resiliencia se determina como el conjunto de conocimientos y técnicas científicas aplicadas a la resolución de situaciones de accidentes que se han presentado y que han afectado las actividades cotidianas en los procesos, para que dichas experiencias al implementar mejoras, nunca más se vuelvan a presentar situaciones de accidentes y orígenes de enfermedades, que lleven a las personas a no asistir a los horarios de trabajo, estas enfermedades pueden llevar a absentismos, originados por baja capacidad de energía o desmotivación.

Desde la Corporación Universitaria Minuto de Dios - UNIMINUTO, la resiliencia se constituye una competencia personal del futuro egresado, el cual sea capaz de afrontar con éxito las situaciones y experiencias dolorosas y problemáticas. Se constituye como una competencia porque integra procesos cognitivos, afectivos, relacionales y conductuales que hacen posible el desarrollo (con éxito) de actuaciones de prevención y de intervención ante las situaciones de riesgo y las consecuencias que éstos puedan tener. Aunque tradicionalmente la resiliencia se asociaba a características personales y a situaciones traumáticas concretas, especialmente las padecidas durante la infancia, está visto que desde UNIMINUTO se busca tener una concepción más amplia y diferente de la resiliencia, por cuatro razones:

1. En primer lugar la resiliencia constituye más que una competencia un conjunto de rasgos personales. Además, todas las personas pueden ser sujetos resilientes, no sólo los niños.

2. El abanico de problemas asociados a la resiliencia es mucho más amplio que las meras situaciones traumáticas.

3. El sistema educativo y las familias deben ser los responsables de la educación de la competencia en resiliencia.

4. La resiliencia así concebida ha de convertirse en una meta-competencia crítica y transversal en los tiempos actuales, que debe abordarse en todos los niveles de la Educación, desde la Educación media hasta los escenarios universitarios. 
Desde esta perspectiva, las Instituciones de Educación Superior deben favorecer el desarrollo de la resiliencia como alternativa educativa y como una vía de desarrollo socio-personal, dentro de un enfoque sistémico integrado. Se debe propender en los elementos de un sistema educativo para atender las pautas o secuencias interactivas que activan los procesos de resiliencia. De mismo modo, se genera el siguiente cuestionamiento ¿qué podrían hacer las IES y los profesores (y por analogía los padres y las familias) para fomentar el aprendizaje de competencias de resiliencia? Al respecto se señalan algunos aspectos que se consideran desde la Facultad de Ingeniería para fortalecer este proceso y constituir propuestos de interés:

- Asumir una pedagogía basada en competencias, y aceptar que la resiliencia constituye una competencia que integra elementos cognitivos, afectivos, sociales y conductuales.

- Generar una cultura de centro y un liderazgo pedagógico centrado en el desarrollo de la resiliencia.

- Ser una competencia transversal integrada en el proceso de enseñanza y aprendizaje de las demás competencias. Así considerada la resiliencia adquiriría la categoría de competencia básica, tal y como se conciben las competencias básicas en la legislación educativa española.

- La competencia de resiliencia debe incluirse en todos los niveles del sistema educativo.

- Utilizar estrategias de enseñanza, actividades y recursos basados en el descubrimiento, la exploración, la autonomía, la iniciativa, la libertad y la auto-suficiencia del estudiante para la construcción del conocimiento enfocado en procesos de investigación.

- Adoptar un rol de profesor con mayor contenido orientador y, en cualquier caso, como figura significativa de apego seguro y generadora de auto-estima. $Y$ también de fomento de saludables relaciones personales.

- Crear ambientes de aprendizaje caracterizados por el optimismo, el sentido crítico, la confianza, la creatividad, el asertividad, el juego y el sentido del humor.

- Potenciar el hecho de que los procesos de enseñanza y aprendizaje desarrollen la responsabilidad y la ética.

- Reforzar y modelar para que los problemas - no sólo los académicos-se transformen en oportunidades.

- Adoptar actitudes de solidaridad y comprensión.

- Favorecer el auto-conocimiento, así como el conocimiento y la aceptación de la realidad, al tiempo que se fomenta el crecimiento social y personal.

- Evitar la humillación, el ridículo, la desvalorización y la indiferencia que afectan de forma negativa a la autoestima y a la confianza que la persona tiene en sí misma y en los demás.

- Aceptar la diversidad y la igualdad, y saber que cada persona tiene expectativas, dificultades y necesidades diferentes a las de los demás, por más que todos seamos nuestros semejantes.

- Desarrollar la escucha, la expresión verbal y no verbal, la comunicación en general.

- Poner límites, tener comportamientos tranquilizadores y hacer observaciones que ayuden a mejorar la formación.

- Fomentar el cambio de punto de vista y mirar de otra manera para observar la belleza que hay en todas las cosas, no sólo los aspectos dolorosos.

- Cambiar la visión reactiva por la preventiva, previniendo riesgos. E intervenir y corregir cuando proceda. 
- Establecer reglas, límites y un orden sin sobrecargar al estudiante, y siempre en función de su etapa de desarrollo, situación y circunstancias.

- Fomentar las relaciones interpersonales y la expansión del sujeto a otros contextos, para que los estudiantes no permanezcan restringidos a un pequeño espacio socio-geográfico.

- Utilizar múltiples recursos y actividades en el desarrollo del proceso de enseñanza y aprendizaje.

- Orientar y potenciar la auto-orientación por parte del alumno.

Los centros educativos incluidas las familias, colegios e Instituciones de Educación Superior) constituyen los contextos apropiados para la socialización de las personas, y es en dichos contextos donde ellos manifiestan con más claridad sus dificultades en la realización de las tareas y en el aprendizaje de las competencias propias de las etapas evolutivas en las que se encuentran. Es por eso que la contribución del sistema educativo al desarrollo de la resiliencia es decisiva e imprescindible. Por su parte, los profesionales asumen un rol importante en el ámbito de la prevención, la detección y la intervención ante la resiliencia, especialmente cuando alguno de los estudiantes está sufriendo algún riesgo o se están vulnerando sus derechos.

Julio César Rivera Rodríguez Editor 